\title{
The Long-term Effectiveness of a Community-based Lifestyle Intervention on Tobacco-related Habits in Adolescent Boys and Girls: Tehran Lipid and Glucose Study
}

\section{Hasti Masihay-Akbar}

Research Center for Social Determinants of Health, Research Institute for Endocrine Sciences, Shahid Beheshti University of Medical Sciences,

Parisa Amiri ( $\square$ amiri@endocrine.ac.ir)

Research Center for Social Determinants of Health, Research Institute for Endocrine Sciences, Shahid Beheshti University of Medical Sciences,

\section{Marjan Rezaei}

Research Center for Social Determinants of Health, Research Institute for Endocrine Sciences, Shahid Beheshti University of Medical Sciences,

\section{Sara Jalali-Farahani}

Research Center for Social Determinants of Health, Research Institute for Endocrine Sciences, Shahid Beheshti University of Medical Sciences,

\section{Leila Cheraghi}

Research Center for Social Determinants of Health, Research Institute for Endocrine Sciences, Shahid Beheshti University of Medical Sciences,

\section{Amir Abbas Momenan}

Prevention of Metabolic Disorders Research Center, Research Institute for Endocrine Sciences, Shahid Beheshti University of Medical Sciences

\section{Fereidoun Azizi}

Endocrine Research Center, Research Institute for Endocrine Sciences, Shahid Beheshti University of Medical Sciences

\section{Research Article}

Keywords: adolescents, cigarette smoking, hookah smoking, passive smoking, community-based intervention

Posted Date: June 24th, 2021

DOI: https://doi.org/10.21203/rs.3.rs-572420/v1 
License: (c) (i) This work is licensed under a Creative Commons Attribution 4.0 International License. Read Full License 


\section{Abstract}

Background: To assess the long-term effectiveness of a community-based intervention on cigarette, passive, and hookah smoking in adolescent boys and girls.

Methods: 1159 adolescents who participated in the Tehran Lipid and Glucose Study (TLGS) between 2001 and 2004 were followed for 12 years (every-three-year follow-ups). Participants in the intervention area received lifestyle interventions in the settings of family, schools, and community. After excluding those with missing baseline parental data $(n=66)$, complete parental data of 1093 adolescents was used for cluster analysis, and families were classified as low- and high-risk. Afterward, 296 individuals who did not complete intervention/follow-ups were excluded. The GEE analysis was performed on 797 adolescents (369 boys) to assess the intervention effect on tobacco-related habits; 605 and 192 resided in the control and intervention area, respectively.

Results: Mean age of adolescents was $15.21 \pm 1.95$ years at baseline. Adolescents living in high-risk families were more at risk of cigarette, passive, and hookah smoking. The intervention decreased the odds of cigarette and passive smoking by $38 \%$ and $57 \%$, respectively. The intervention was not successful in reducing the risk of hookah smoking in adolescents. After sex-specific analysis, the intervention reduced the risk of current cigarette smoking by $40 \%$ only in boys and passive smoking in both sexes.

Conclusions: Targeting lifestyle behaviors in adolescents and their families in a community setting reduces cigarette smoking in school-aged boys and protects both sexes from secondhand smoke; findings that could be valuable for designing future health promotion interventions focusing on adolescents smoking.

Trial registration: This study is registered at Iran Registry for Clinical Trials (IRCT), a WHO primary registry (http://irct.ir). The registry date is 29/10/2008; (IRCTID: IRCT138705301058N1).

\section{Introduction}

Tobacco smoking as a leading preventable risk factor for non-communicable diseases shows a decreasing trend in adolescents worldwide, except for the Middle Eastern and African countries (1). Hookah, on the other hand, is becoming globally popular among teenagers, especially in the Middle-East region (2). As a country in lifestyle transition, smoking in Iran showed an upward shift through the last decades, especially in women and youngsters (3). Global Youth Tobacco Survey 2016 reported approximately $25 \%$ passive smoking and a four-fold prevalence of hookah use compared to current cigarette smoking in 13-15 year Iranian students (4).

Among tobacco control studies in children mainly focused on cigarette smoking (5-7), behavioral interventions are most promising (5). Limited studies considered hookah use, and little is known about interventions that can reduce hookah consumption in the general population $(8,9)$. Although schools 
have always been convenient settings to deliver children-focused interventions, review of the literature suggests that tobacco prevention using just the school curricula is less effective. In order to obtain better results, school-based programs should be integrated with other initiatives to form comprehensive community programs. Many anti-tobacco programs target families, as parental factors are among several influential factors in the formation and continuation of smoking behavior in the offspring (10). The co-occurrence and inter-relations of parental risk factors in the family context affect children's tobacco use, and alters interventions effectiveness (11). Although family-centered interventions have shown some effectiveness in smoking prevention in children, the evidence is not strong enough (12). The methodological and design heterogeneity among existing interventions and behavioral programs make it difficult to draw conclusions about the best strategy, especially when maintaining the long-term effects.

In the Eastern-Mediterranean countries, there are only a few successful short-term anti-tobacco interventions in adolescents (13-15); hence adolescents smoking still requires specific planning. In Iran, in particular, interventions have mostly targeted cigarette rather than other forms of tobacco use (16-19). Our previous study in Iran (11) showed that although a multidisciplinary healthy lifestyle intervention could postpone smoking initiation and reduce the risk of becoming a current smoker in non-smoking adolescents, it could not prevent continuation in those who initiated. Previous results have led us to answer whether this success in prevention can reduce the prevalence of cigarette smoking in the population level in the long-term and whether this intervention can simultaneously reduce the prevalence of other direct and indirect forms of tobacco. With all that said, we aimed to investigate the timedependent effects of a community-based lifestyle intervention on the cigarette, hookah, and passive smoking in an urban population of Iranian adolescent boys and girls over 12 years. Data for the current study was derived from the Tehran Lipid and Glucose Study (TLGS) -a unique family-based cohort in the Middle East- which enabled us to consider parental risks in assessing the intervention effect.

\section{Methods}

\section{Study participants}

The TLGS is an ongoing population-based cohort in Tehran, capital of Iran; it has two main junctures: Phase I, a cross-sectional study for determining the prevalence of NCDs and their risk factors, implemented from 1999 to 2001; and every-three-years subsequent follow-ups, starting from phase II (2001-present). The study is being conducted in district No.13 of Tehran, as its population is stable, their age and socio-economic status are generalizable to the whole population of Tehran, and documented data is available for more than $90 \%$ of the families. Three of the 20 health centers of district No.13 were selected by multistage cluster random sampling method, and from those health centers, data of 15,005 residents (aged $\geq$ three years) were collected. After baseline assessment, a community-based intervention was designed with the main aim of tackling NCDs through lifestyle modification. One of the three health centers was selected for implementing intervention; the reason was geographical location. This center was far from the other two; this way we could minimize cross-contamination. Assignment of participants to the intervention and control groups was based on their area of residency, meaning that residents under 
the coverage of the intervention medical center received the intervention. The rationale and design of the TLGS have been described elsewhere (20). This TLGS is registered at Iran Registry for Clinical Trials (IRCT), a WHO primary registry (http://irct.ir; IRCTID: IRCT138705301058N1, date: 29/10/2008). This study was approved by the Ethical Committee of Research Institute for Endocrine Sciences and the National Research Council of the Islamic Republic of Iran (no. EC 121).

The current study population was restricted to adolescents (12-18 years) who participated in phase II (2001-2004) of the TLGS (baseline of the current study) with known membership status in the intervention/control group. These 1159 adolescents were followed for a median of 12.4 years (four follow-ups). For the current analysis, after excluding those with missing baseline data on parental factors $(n=66)$, complete data of 1093 adolescents was used for cluster analysis. Afterward, 296 individuals who lost to complete intervention or follow-up were excluded. In order to assess the intervention effect, the final GEE analysis was performed on 797 adolescents (369 boys and 428 girls); 605 and 192 of whom resided in the control and intervention area, respectively (Fig. 1).

\section{Intervention}

The design of the TLGS intervention has been described previously (20). Briefly, the intervention was adapted from the American Heart Association guidelines, North Karelia project, and Knowledge, Attitude and Practice (KAP) study in the TLGS population (21-23). The current anti-smoking intervention is a part of multi-component lifestyle intervention implemented in the contexts of school, family, and community. The substantive content of the intervention in each context was prepared by the TLGS scientific committee and delivered under the supervision of the intervention health center.

\section{Schools}

A large part of the current intervention was implemented in schools. In total, 12 schools in the intervention area were selected as "Health Promoting Schools"; these schools were located at the farthest points from the control area. All principals and volunteer teachers were annually trained by TLGS scientific committee. The school-based subprogram is inspired by social learning theory (24) and modified with principles of Iranian culture. Life skill training offered in TLGS school-based component is designed to teach students how to live tobacco-free by targeting their knowledge, attitude, and skills. It targeted all school community (students, families, teachers, and other staff) and consisted of four main components: 1) classroom curriculum and practice, 2) peer teaching, 3) anti-tobacco policies in schools, and 4) parents' cooperation. The educational packages for classroom curriculum were designed to improve students' knowledge and skills to modify their lifestyle and avoid smoking. Each academic year, nine educational sessions (45 min each) were held by trained teachers for students in all grades and then repeated at the beginning of each academic year for the first-grade students. Representative students formed "school health society" and worked together to improve healthy lifestyles in all students under the supervision of trained teachers. Anti-smoking policies banned smoking for the whole school community. Regular parent-teacher meetings were held to introduce the school-based programs and help families create a supportive environment for 
students at home to lead a tobacco-free lifestyle. They included a series of discussions about the extent of NCD risk factors among students and their families, enabling parents to implement practical aspects of the program. Process evaluation results indicated that almost $70 \%$ of planned interventions in the context of schools were successfully implemented, and all educational sessions were completely held. However, some families refused to participate in related programs.

\section{Families}

The main deliverers in this context were health volunteers under the supervision of the intervention health center. At the primary prevention level, families were invited for group sessions and face-to-face counseling conducted in the healthcare center. Families received a seasonal newsletter "Courier of Health" regarding healthy lifestyle and smoking cessation. Pamphlets/booklets about lifestyle management were distributed two to four times per year to all families in the intervention area. Telephone surveys showed that $50 \%$ of households had received and paid attention to educational pamphlets and health newsletters. At secondary prevention level, all smokers were invited to participate in a motivational consultation and then referred to a cessation clinic to help smokers quit smoking.

\section{Community}

Various sectors including, municipality, police, media, and community leaders were involved in this part. The community-based intervention consisted of health promotion advertisements in the intervention area and public education through community gatherings (two to four times annually), including social events such as World No Tobacco Day and World Diabetes Day and religious ceremonies, particularly in Ramadan. On these occasions, public conferences were held in one of the largest local amphitheaters in the intervention area to deliver the key messages regarding lifestyle modifications. More than $80 \%$ of the households participated in at least one public gathering between every two examinations.

\section{Measures}

Trained interviewers obtained information regarding socio-demographic characteristics, smoking habits and physical activity for both adolescents and parents. Smoking habits in adolescents were assessed by the following questions "have you smoked cigarette during the last 30 days?" Smoking cigarette every day or some days in the last month was considered as "Yes" and never smoking as "No". In terms of hookah smoking, the same question was asked "have you smoked hookah during the last 30 days?" and the answer was either "Yes" as every day or some days of hookah smoking or "No" as never. Passive smoking was defined as being exposed to someone else's smoking at home. Smoking status in adults was defined as: 1) current smokers which includes those who smoked any type of tobacco daily or occasionally; 2) non-smokers including individuals who were ex- or never-smokers. Physical activity in parents was assessed by the Persian validated version of the Modifiable Activity Questionnaire (MAQ) $(25)$ and was categorized as low $(<600)$, moderate $(600-3000)$ and high $(\geq 3000)$ physical activity.

\section{Statistical analysis}


Continuous and categorical data were described using mean \pm SD and frequency (percent) respectively. Adolescents were classified in low- and high-risk parental groups considering their family characteristics (age, education, employment, smoking, physical activity), using two-step cluster analysis. Two-step cluster analysis, suitable for both continuous and categorical variables, and based on Akaike and Bayesian information criteria, was used to extract the optimal and inherent parental risk groups. The clustering process can be referenced in detail in our previous report (10). Independent samples t-test and chi-square test were used to compare continuous and categorical variables across groups respectively. Using the Generalized Estimating Equation (GEE) with "binomial-logit" link function and "independent" working correlation matrix, the trends of smoking status including current and passive cigarette smoking as well as hookah smoking status (yes $=1$, no $=0$ ) were evaluated over time. The effects of intervention, time and their interaction effect were tested on smoking status over 12 years of follow up. Statistical analysis was done in 2020 using IBM SPSS Statistics 23 , and $P<0.05$ was considered as the significance level.

\section{Results}

Baseline characteristics of adolescents and parents are shown in Table 1. Mean age of adolescents ( $46.3 \%$ boys) was $15.22 \pm 1.95$ years with no significant difference between the intervention and control groups. The intervention group included more high-risk families $(73.4 \%)$ than control $(55.5 \%)$ groups $(\mathrm{P}<$ 0.001). Except for mothers' smoking and fathers' physical activity, other socio-behavioral variables were significantly different between study groups $(p<0.05)$. Details of parental risk clusters and their contributing factors have been reported in Fig. 1-Appendix and Table 1-Appendix. Paternal education was the most important factor in the clustering. In the high-risk cluster, most mothers and nearly $80 \%$ of fathers were illiterate or had primary education. $42 \%$ of fathers were smoker in the high-risk group, compared to $2.5 \%$ in low-risk cluster. 
Table 1

Baseline characteristics of study participants in intervention and control groups

\begin{tabular}{|c|c|c|c|c|}
\hline Adolescent characteristics & $\begin{array}{l}\text { Total } \\
(n=797)\end{array}$ & $\begin{array}{l}\text { Control } \\
(n=605)\end{array}$ & $\begin{array}{l}\text { Intervention } \\
(n=192)\end{array}$ & p-value \\
\hline Age (year) & $15.22 \pm 1.95$ & $15.14 \pm 1.95$ & $15.50 \pm 1.93$ & 0.66 \\
\hline Sex & & & & 0.75 \\
\hline Boys & $369(46.3 \%)$ & $282(46.6 \%)$ & $87(45.3 \%)$ & \\
\hline Girls & $428(53.7 \%)$ & $323(53.4 \%)$ & $105(54.7 \%)$ & \\
\hline \multicolumn{5}{|l|}{ Maternal characteristics } \\
\hline Age (year) & $42.12 \pm 6.49$ & $41.36 \pm 6.16$ & $44.51 \pm 6.92$ & 0.024 \\
\hline Education & & & & 0.003 \\
\hline Illiterate-primary & $351(44 \%)$ & $250(41.3 \%)$ & $101(52.6 \%)$ & \\
\hline High school-diploma & $300(37.6 \%)$ & $230(38 \%)$ & $70(36.5 \%)$ & \\
\hline Academic degree & $146(18.3 \%)$ & $125(20.7 \%)$ & $21(10.9 \%)$ & \\
\hline Employment & & & & 0.002 \\
\hline Employed & $62(7.8 \%)$ & $57(9.4 \%)$ & $5(2.6 \%)$ & \\
\hline Housewives & 735 (92.2\%) & $548(90.6 \%)$ & $187(97.4 \%)$ & \\
\hline Smoking status & & & & 0.28 \\
\hline Yes & $36(4.5 \%)$ & $30(5 \%)$ & $6(3.1 \%)$ & \\
\hline No & 757 (95\%) & $571(95 \%)$ & $186(96.9 \%)$ & \\
\hline Physical activity* & & & & 0.003 \\
\hline Low & $190(24.1 \%)$ & $137(22.9 \%)$ & $53(27.7 \%)$ & \\
\hline Moderate & $464(58.9 \%)$ & $343(57.5 \%)$ & $121(63.4 \%)$ & \\
\hline High & $134(17 \%)$ & $117(19.6 \%)$ & $17(8.9 \%)$ & \\
\hline \multicolumn{5}{|l|}{ Paternal characteristics } \\
\hline Age (year) & $48.20 \pm 7.59$ & $47.35 \pm 7.13$ & $50.90 \pm 8.34$ & 0.003 \\
\hline Education & & & & 0.006 \\
\hline Illiterate-primary & $427(53.6 \%)$ & 307 (50.7\%) & $120(62.5 \%)$ & \\
\hline
\end{tabular}

* Physical activity was defined as low (<600 MET-min/wk), moderate (600-3000 MET-min/wk), and high ( $\geq 3000$ MET-min/wk). 


\begin{tabular}{|c|c|c|c|c|}
\hline Adolescent characteristics & $\begin{array}{l}\text { Total } \\
(n=797)\end{array}$ & $\begin{array}{l}\text { Control } \\
(n=605)\end{array}$ & $\begin{array}{l}\text { Intervention } \\
(n=192)\end{array}$ & p-value \\
\hline High school-diploma & $324(40.7 \%)$ & $257(42.5 \%)$ & $67(34.9 \%)$ & \\
\hline Academic degree & $46(5.8 \%)$ & $41(6.8 \%)$ & $5(2.6 \%)$ & \\
\hline Employment & & & & $<0.001$ \\
\hline Employed & $645(80.9 \%)$ & $510(84.3 \%)$ & $135(70.3 \%)$ & \\
\hline Un-employed & $152(19.1 \%)$ & $95(15.7 \%)$ & $57(29.7 \%)$ & \\
\hline Smoking status & & & & 0.008 \\
\hline Yes & 208 (26.1\%) & 172 (28.4\%) & $36(18.8 \%)$ & \\
\hline No & 589 (73.9\%) & 433 (71.6\%) & $156(81.3 \%)$ & \\
\hline Physical activity & & & & 0.48 \\
\hline Low & $296(46.1 \%)$ & $219(44.8 \%)$ & $77(50.3 \%)$ & \\
\hline Moderate & $183(28.5 \%)$ & $142(29 \%)$ & $41(26.8 \%)$ & \\
\hline High & $163(25.4 \%)$ & $128(26.2 \%)$ & $35(22.9 \%)$ & \\
\hline Parental Cluster & & & & $<0.001$ \\
\hline Low risk & $320(40.2 \%)$ & $269(44.5 \%)$ & $51(26.6 \%)$ & \\
\hline High risk & $477(59.8 \%)$ & $336(55.5 \%)$ & $141(73.4 \%)$ & \\
\hline
\end{tabular}

Figure 2 illustrates the prevalence of current cigarette smoking, passive smoking, and hookah smoking over the follow-ups. Cigarette smoking had no significant difference between the intervention and control, any time. Passive smoking was significantly more prevalent in control group at baseline, 1st and 2nd follow-ups. Although hookah smoking was always less prevalent in the intervention group, the difference was not significant in any follow-up.

The effects of intervention and time on tobacco smoking are shown in Table 2. Based on GEE results, the interaction effect of intervention*time was not significant on cigarette smoking (Wald's Chi-Square $=0.75$, $\mathrm{DF}=4, \mathrm{P}=0.94)$; therefore, it was excluded in the final GEE models. Regardless of sex, the intervention significantly decreased the odds of cigarette smoking by $38 \%(\mathrm{OR}=0.62,95 \% \mathrm{Cl}=0.40-0.97 ; \mathrm{P}=0.04)$. Compared to baseline, the odds of cigarette smoking showed an increasing trend from the first $(\mathrm{OR}=4.02$, $95 \% \mathrm{Cl}=2.31-7.02 ; \mathrm{P}<0.001)$ to the last $(\mathrm{OR}=19.14,95 \% \mathrm{Cl}=10.89-33.66 ; \mathrm{P}<0.001)$ follow-up. Highrisk families had higher odds $(\mathrm{OR}=1.97,95 \% \mathrm{Cl}=1.35-2.88 ; \mathrm{P}<0.001)$ of cigarette smoking. Girls had lower odds of cigarette smoking, compared to boys $(\mathrm{OR}=0.12,95 \% \mathrm{Cl}=0.08-0.19 ; \mathrm{P}<0.001)$. Sex- 
specific analysis showed that the positive effect of intervention in reducing the odds of cigarette smoking was seen only in boys $(\mathrm{OR}=0.60,95 \% \mathrm{Cl}=0.37-0.99 ; \mathrm{P}=0.05)$ not in girls $(\mathrm{OR}=0.69,95 \% \mathrm{Cl}=0.26-1.80$; $P=0.45)$. 
Table 2

The total and sex-specific effects of intervention on tobacco smoking in different follow-ups.

Cigarette smoking

Predictors
OR $(95 \% \mathrm{Cl}) \quad \mathrm{P}$
Passive smoking

OR $(95 \% \mathrm{Cl}) \quad \mathrm{P}$
Hookah smoking*

OR $(95 \% \quad P$

$\mathrm{Cl})$

Total Group

$\begin{array}{lllllll}\text { Intervention } & 0.62(0.40- & 0.04 & 0.43(0.28- & < & 0.84 & 0.25 \\ & 0.97) & & 0.64) & 0.001 & (0.62- & \\ & & & & & 1.13) & \end{array}$

Time

$\begin{array}{lllllll}\text { 1st Follow- } & 4.02(2.31- & < & 0.67(0.56- & < & \text { Ref }^{\text {a }} & \\ \text { up } & 7.02) & 0.001 & 0.80) & 0.001 & & \\ \text { 2nd Follow- } & 8.00(5.25- & < & 0.46(0.36- & < & 2.50 & < \\ \text { up } & 15.41) & 0.001 & 0.58) & 0.001 & (1.99- & 0.001 \\ & & & & & 3.15) & \end{array}$

3rd Follow- 12.39 (7.06-

up

$<\quad 0.32(0.24-$

21.73) 0.001

$0.42)$

0.001

2.30

(1.83-

$<$

2.90)

4th Follow- 19.14 (10.89-

up

33.66)

0.001

$0.19(0.13-<$

$0.28)$

0.001

2.19

(1.72-

2.75)

parental

cluster

$\begin{array}{lllllll}\text { High-risk } & 1.97(1.35- & < & 3.50(2.41- & < & 1.46 & 0.005 \\ & 2.88) & 0.001 & 5.09) & 0.001 & (1.12- & \\ & & & & & 1.90) & \end{array}$

Ado. Sex

$\begin{array}{llllll}0.12(0.08- & < & 1.90(1.40- & < & 0.37 & < \\ 0.19) & 0.001 & 2.60) & 0.001 & (0.29- & 0.001 \\ & & & & 0.48) & \end{array}$

\begin{tabular}{|c|c|c|c|c|c|}
\hline Ado. Age & $\begin{array}{l}1.11(1.01- \\
1.22)\end{array}$ & 0.002 & $\begin{array}{l}0.96(0.89- \\
1.04)\end{array}$ & 0.37 & $\begin{array}{l}1.01 \\
(0.95- \\
1.08)\end{array}$ \\
\hline
\end{tabular}

Boys Group

\begin{tabular}{|c|c|c|}
\hline Intervention & $\begin{array}{l}0.60(0.37- \\
0.99)\end{array}$ & 0.0 \\
\hline
\end{tabular}

Time

* evaluating hookah smoking started from the 1st follow-up, therefore 1 st follow-up was considered as baseline and three subsequent measurements were conducted over the study duration. 
Cigarette smoking

\begin{tabular}{|c|c|c|c|c|c|c|}
\hline $\begin{array}{l}1 \text { st Follow- } \\
\text { up }\end{array}$ & $\begin{array}{l}3.66(2.07- \\
6.45)\end{array}$ & $<001$ & $\begin{array}{l}0.53(0.40- \\
0.72)\end{array}$ & $\begin{array}{l}< \\
0.001\end{array}$ & $\operatorname{Ref}^{a}$ & \\
\hline $\begin{array}{l}\text { 2nd Follow- } \\
\text { up }\end{array}$ & $\begin{array}{l}7.98(4.64- \\
13.74)\end{array}$ & $<.001$ & $\begin{array}{l}0.23(0.13- \\
0.38)\end{array}$ & $<001$ & $\begin{array}{l}2.22 \\
(1.62- \\
3.06)\end{array}$ & $<001$ \\
\hline $\begin{array}{l}\text { 3rd Follow- } \\
\text { up }\end{array}$ & $\begin{array}{l}11.64(6.56- \\
20.66)\end{array}$ & $<0.001$ & $\begin{array}{l}0.13(0.07- \\
0.25)\end{array}$ & $<0.001$ & $\begin{array}{l}2.15 \\
(1.56- \\
2.94)\end{array}$ & $\dot{0} 001$ \\
\hline $\begin{array}{l}\text { 4th Follow- } \\
\text { up }\end{array}$ & $\begin{array}{l}16.03(9.00- \\
28.54)\end{array}$ & $<0.001$ & $\begin{array}{l}0.10(0.04- \\
0.22)\end{array}$ & $<.001$ & $\begin{array}{l}2.03 \\
(1.47- \\
2.81)\end{array}$ & $<.001$ \\
\hline $\begin{array}{l}\text { parental } \\
\text { cluster }\end{array}$ & & & & & . & \\
\hline High-risk & $\begin{array}{l}2.10(1.36- \\
3.24)\end{array}$ & 0.001 & $\begin{array}{l}5.27(2.70- \\
10.31)\end{array}$ & $\dot{0} 001$ & $\begin{array}{l}1.68 \\
(1.20- \\
2.36)\end{array}$ & 0.003 \\
\hline Ado. Age & $\begin{array}{l}1.17(1.04- \\
1.30)\end{array}$ & 0.005 & $\begin{array}{l}0.10(0.88- \\
1.13)\end{array}$ & 0.99 & $\begin{array}{l}1.09 \\
(1.00- \\
1.18)\end{array}$ & 0.04 \\
\hline
\end{tabular}

Intervention

0.69
$1.80)$ (0.26- $^{(26}$

0.45

$0.43(0.25-\quad 0.002$

$0.74)$

Hookah smoking*

\section{cols}

\section{Girls Group}

\begin{tabular}{|c|c|c|c|c|c|c|}
\hline 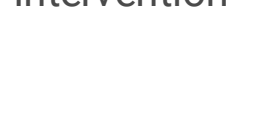 & $1.80)$ & & $0.74)$ & & $\begin{array}{l}(0.46- \\
1.22)\end{array}$ & \\
\hline \multicolumn{7}{|l|}{ Time } \\
\hline $\begin{array}{l}1 \text { st Follow- } \\
\text { up }\end{array}$ & Ref & . & $\begin{array}{l}0.78(0.63- \\
0.95)\end{array}$ & 0.01 & Ref a & \\
\hline $\begin{array}{l}\text { 2nd Follow- } \\
\text { up }\end{array}$ & $\begin{array}{l}2.71(1.20- \\
6.10)\end{array}$ & 0.02 & $\begin{array}{l}0.66(0.51- \\
0.85)\end{array}$ & 0.001 & $\begin{array}{l}2.94 \\
(2.08- \\
4.16)\end{array}$ & $\begin{array}{l}< \\
0.001\end{array}$ \\
\hline $\begin{array}{l}\text { 3rd Follow- } \\
\text { up }\end{array}$ & $\begin{array}{l}2.90(1.16- \\
7.27)\end{array}$ & 0.02 & $\begin{array}{l}0.49(0.35- \\
0.65)\end{array}$ & $\begin{array}{l}<.001 \\
0.00\end{array}$ & $\begin{array}{l}2.60 \\
(1.84- \\
3.66)\end{array}$ & $<0.001$ \\
\hline $\begin{array}{l}\text { 4th Follow- } \\
\text { up }\end{array}$ & $\begin{array}{l}7.05(2.78- \\
17.91)\end{array}$ & $\begin{array}{l}< \\
0.001\end{array}$ & $\begin{array}{l}0.27(0.17- \\
0.43)\end{array}$ & $\begin{array}{l}< \\
0.001\end{array}$ & $\begin{array}{l}2.50 \\
(1.72- \\
3.62)\end{array}$ & $\begin{array}{l}< \\
0.001\end{array}$ \\
\hline $\begin{array}{l}\text { parental } \\
\text { cluster }\end{array}$ & & & & & . & . \\
\hline
\end{tabular}

* evaluating hookah smoking started from the 1 st follow-up, therefore $1 \mathrm{st}$ follow-up was considered as baseline and three subsequent measurements were conducted over the study duration. 
Cigarette smoking

High-risk

$1.45(0.70-$

3.04)

Ado. Age

$0.91(0.79-$

1.07)
0.31

0.26
Passive smoking

$2.93(1.86-$

4.63)

$<$

0.001

$0.95(0.85-$

1.05)

0.28
Hookah smoking*

1.17

(0.78-

1.75)

0.91

(0.83-

1.00)

0.44

0.07

* evaluating hookah smoking started from the 1st follow-up, therefore 1 st follow-up was considered as baseline and three subsequent measurements were conducted over the study duration.

The interaction effect of intervention*time was not significant on passive smoking (Wald's Chi-Square $=$ $0.97, \mathrm{DF}=3, \mathrm{P}=0.91$ ), therefore excluded from the final GEE models. Intervention reduced the odds of passive smoking in the total population by $57 \%(\mathrm{OR}=0.43,95 \% \mathrm{Cl}=0.28-0.64 ; \mathrm{P}<0.001)$. Compared to baseline, the odds of passive smoking in the total population had a decreasing trend from the first (OR = $0.67,95 \% \mathrm{Cl}=0.56-0.80 ; \mathrm{P}<0.001)$ to the last $(\mathrm{OR}=0.19,95 \% \mathrm{Cl}=0.13-0.28 ; \mathrm{P}<0.001)$ follow-up. The odds of being a passive smoker was significantly higher in high-risk families $(\mathrm{OR}=3.50,95 \% \mathrm{Cl}=2.41-$ 5.09; $\mathrm{P}<0.001)$. Considering adolescents' sex and age, while girls had significant higher odds of being a passive smoker $(\mathrm{OR}=1.90,95 \% \mathrm{Cl}=0.1 .40-2.60 ; \mathrm{P}<0.001)$, the effect of age was not significant $(\mathrm{P}=$ 0.37). Sex-specific analysis showed that the intervention reduced the odds of passive smoking in boys by $58 \%(\mathrm{OR}=0.42,95 \% \mathrm{Cl}=0.23-0.75 ; \mathrm{P}=0.003)$, and in girls by $57 \%(\mathrm{OR}=0.43,95 \% \mathrm{Cl}=0.25-0.74 ; \mathrm{P}=$ $0.002)$.

In terms of hookah smoking, the interaction effect of intervention*time was not significant (Wald's ChiSquare $=2.13, D F=3, P=0.55)$ and was excluded from the final GEE models. However, the intervention was not successful in reducing the risk of hookah smoking in adolescents $(\mathrm{OR}=0.84,95 \% \mathrm{Cl}=0.62-1.13$; $P=0.25)$. Living in high-risk families increased the risk of hookah smoking $(\mathrm{OR}=1.41,95 \% \mathrm{Cl}=1.13-$ $1.75 ; \mathrm{P}=0.002)$. Girls $(\mathrm{OR}=2.30,95 \% \mathrm{Cl}=1.85-2.58 ; \mathrm{P}<0.001)$ had lower odds of hookah smoking; while, age had no significant effect. Moreover, after sex-specific analysis, intervention did not reduce hookah use in boys $(\mathrm{OR}=0.88,95 \% \mathrm{Cl}=0.59-1.29 ; \mathrm{P}=0.51)$ and girls $(\mathrm{OR}=0.75,95 \% \mathrm{Cl}=0.46-1.22 ; \mathrm{P}=$ 0.25).

\section{Discussion}

The current study aimed to evaluate the effects of a multi-component community-based intervention on tobacco habits among adolescents in a Middle-Eastern population. Based on the results, adolescents living with high-risk families were more at risk of all tobacco-related outcomes (i.e., cigarette, passive, and hookah smoking). The TLGS intervention -regardless of sex and the family risks- showed promising longterm effects on adolescents' cigarette and passive smoking, with no effect on hookah smoking. Further sex-stratified analysis showed that while reducing the risk of passive smoking in both sexes, the intervention decreased the likelihood of cigarette smoking only in boys and had no effect on hookah 
smoking in either sex. None of the observed effects of the intervention in the present study was timedependent.

Despite the general increasing trend of current cigarette smoking in the whole population during the study (which seems reasonable considering the increasing age of the study population), the risk of current cigarette smoking in the intervention group was $38 \%$ lower than the control; the intervention effect did not differ between the follow-ups. Various delivery platforms have been introduced for tobacco control in youth (particularly cigarette use), most of which are school-based, either isolated or combined with other components such as family- or community-based initiatives. Among isolated school-based programs, those with combined social competence and social influence curricula and those involving students were more successful (26). Yet, for larger and more sustained effects, integration with other initiatives for families and community-delivered strategies are needed (6); nevertheless, there is still inconsistency in the long-term sustainability of school-based programs due to heterogeneity in methods and duration. Multicomponent community-delivered plans have been more promising in maintaining their effectiveness in the long run (5-7).

We observed sex differences in the effects of intervention in reducing cigarette smoking. The TLGS intervention resulted in a $40 \%$ reduction in boys' cigarette smoking, with no significant effect on girls. Girls' smoking has surpassed boys' in some developed countries and developing countries gradually step on the same road (27). Despite the stigmatization of female smoking in the Middle East, girls associate this behavior with masculinity; they see smoking as an act of rebellion against gender discrimination in the family and society (28). Gender also affects the adoption of smoking preventive initiatives (29). Accordingly, no supporting evidence has been reported for the effectiveness of gender-nonspecific antismoking programs on girls (30). Given the factors that motivate girls to smoke or quit smoking, researchers recommend gender-specific interventions to be more effective in girls (31).

The TLGS intervention reduced the risk of passive smoking in adolescent boys and girls; this could be attributed to the direct effect of the school-based intervention in raising children's awareness and children may communicate the health messages to other people, including their parents and siblings (32). Accordingly, some school-based intervention changed parents' behaviors and, therefore had the potential to decrease in-home smoking $(33,34)$. However, despite improving children's knowledge and attitudes regarding the health hazards of tobacco smoke, some interventions did not succeed in creating a smokefree home $(35,36)$. It seems that parents should also be directly involved in a school-based program to change in-home smoking behavior. Accordingly, the TLGS school-based intervention is a part of the TLGS community trial that targets children's behavior in the family context and not separately. So, the direct impact of the intervention on the parents could be the other explanation for our success in controlling passive smoking in children. The home environment is one of the most common places where children are exposed to secondhand smoke; interventions directly targeting smoking in adults not only reduce their smoking rate, but make them less likely to smoke in the presence of children and reduce smoking in the home environment (37). 
Regarding hookah consumption in the total study population, we observed a decrease in each follow-up compared to baseline. However, compared to control group, the intervention did not significantly change hookah use in either sex. The literature is sparse and inconclusive about hookah interventions that are mostly on cessation in hookah smokers with only three successful attempts (9). Preventive efforts are even scarcer (8); for example, educating students about tobacco-related health over a six month period in Germany, while having a primary preventive effect against hookah and cigarette, failed to persuade consumers to quit (38). It could be implied that education unaccompanied by additional strategies may have limited short-term effects. Another school-based hookah prevention program in Lebanon succeeded in enhancing the knowledge and shifting the students' attitude against hookah yet had no impact on behavior. Their failure to change behavior was attributed to the short study period, overall positive social context towards hookah, and weak anti-tobacco policy (39). Another important issue in hookah control programs is the lack of consensus on the need to design hookah-specific interventions. The majority of anti-hookah studies today are either the same or derived from existing anti-smoking programs (40); these nonspecific interventions target common determinants of different forms of tobacco. However, despite its similarities with cigarette use, hookah consumption has distinguishing characteristics mostly rooted in the socio-cultural context of the studied community; this has led scientists to shift gradually towards the design of specific interventions for hookah (40).

This study is one of the first efforts to investigate the long-term effectiveness of a community-based intervention on tobacco outcomes in adolescents residing in an Eastern Mediterranean region. Considerable sample size and long-term follow-up of more than 12 years are among the strength of this study. Moreover, as a study conducted in the framework of a family-based cohort, considering the synergic effect of potential parental risk factors resulted in more accurate findings. Some limitations of this study should be noted. First, behavioral information including smoking and physical activity was collected using questionnaire-based methods, increasing possible information bias. Second, the current intervention was conducted in an urban area, and its findings cannot be generalized to Tehran's rural- and sub-urban areas.

\section{Conclusion}

Our results showed that a long-term community-based intervention targeting lifestyle behaviors in adolescents and their families reduces the risk of current cigarette smoking in school-aged boys and protects both sexes from secondhand smoke; findings which could be valuable for designing future health promotion interventions focusing on smoking habits in the early years of life.

\section{Abbreviations}

TLGS: Tehran Lipid and Glucose Study

GEE: Generalized Estimating Equation

OR: Odds Ratio 


\section{Declarations}

\section{Ethics approval and consent to participate}

The study was approved by the Ethical Committee of Research Institute for Endocrine Sciences and the National Research Council of the Islamic Republic of Iran (no. EC 121). Informed consent was obtained from all individual participants included in the study. All procedures were in accordance with the ethical standards of the institutional and/or national research committee and with the 1964 Helsinki declaration and its later amendments or comparable ethical standards.

\section{Consent for publication}

Not applicable.

\section{Trial registration number and date}

This study is registered at Iran Registry for Clinical Trials (IRCT), a WHO primary registry (http://irct.ir). The registry date is 29/10/2008; (IRCTID: IRCT138705301058N1).

\section{Availability of data and materials}

The datasets used and/or analyzed during the current study are available from the corresponding author on reasonable request.

\section{Competing interests}

The authors declare that they have no competing interests.

\section{Funding}

The authors received no financial support for the research, authorship, and/or publication of this article.

\section{Authors' contributions}

HM-A, PA, MR and SJ-F designed the study. AAM participated in acquisition of data. LC carried out the statistical analysis. LC and HM-A contributed to interpretation of data. HM-A, MR and PA drafted the manuscript. FA, PA and AAM supervised and revised the manuscript. All authors read and approved the final manuscript.

\section{Acknowledgements}

The authors would like to express their appreciation to all participants who made this study possible. 


\section{References}

1. Reitsma MB, Fullman N, Ng M, Salama JS, Abajobir A, Abate KH, et al. Smoking prevalence and attributable disease burden in 195 countries and territories, 1990-2015: a systematic analysis from the Global Burden of Disease Study 2015. The Lancet. 2017;389(10082):1885-906.

2. Maziak W, Taleb ZB, Bahelah R, Islam F, Jaber R, Auf R, et al. The global epidemiology of waterpipe smoking. Tobacco control. 2015;24(Suppl 1):i3-i12.

3. Heydari G, Ebn Ahmady A, Lando H, Chamyani F, Masjedi M, Shadmehr M, et al. A qualitative study on a 30-year trend of tobacco use and tobacco control programmes in Islamic Republic of Iran. EMHJ-Eastern Mediterranean Health Journal. 2016;22(5):335-42.

4. WHO. Global Youth Tobacco Survey - Islamic Republic of Iran. 2018.

5. Peirson L, Ali MU, Kenny M, Raina P, Sherifali D. Interventions for prevention and treatment of tobacco smoking in school-aged children and adolescents: a systematic review and meta-analysis. Preventive medicine. 2016;85:20-31.

6. Das JK, Salam RA, Arshad A, Finkelstein Y, Bhutta ZA. Interventions for adolescent substance abuse: An overview of systematic reviews. Journal of Adolescent Health. 2016;59(4):S61-S75.

7. Thomas RE, McLellan J, Perera R. Effectiveness of school-based smoking prevention curricula: systematic review and meta-analysis. BMJ open. 2015;5(3):e006976.

8. Jawad M, Jawad S, Waziry RK, Ballout RA, AkI EA. Interventions for waterpipe tobacco smoking prevention and cessation: a systematic review. Scientific reports. 2016;6:25872.

9. Maziak W, Jawad M, Jawad S, Ward KD, Eissenberg T, Asfar T. Interventions for waterpipe smoking cessation. The Cochrane database of systematic reviews. 2015;2015(7):Cd005549.

10. Amiri P, Masihay-Akbar H, Jalali-Farahani S, Karimi M, Momenan AA, Azizi F. The First Cigarette Smoking Experience and Future Smoking Behaviors Among Adolescents with Different Parental Risk: a Longitudinal Analysis in an Urban Iranian Population. International Journal of Behavioral Medicine. 2020;27(6):698-706.

11. Masihay-Akbar H, Amiri P, Cheraghi L, Momenan AA, Azizi F. The cigarette smoking initiation and continuation in adolescents undergoing a long-term behavioral intervention. Nicotine \& tobacco research: official journal of the Society for Research on Nicotine and Tobacco. 2020.

12. Thomas RE, Baker PRA, Thomas BC. Family-Based Interventions in Preventing Children and Adolescents from Using Tobacco: A Systematic Review and Meta-Analysis. Academic Pediatrics. 2016;16(5):419-29.

13. Ghrayeb FA, Rusli AM, Al Rifai A, Ismail IM. The impact of education program on smoking prevention: an intervention study among 16 to 18 years old in Palestine. Pakistan Journal of Nutrition. 2013;12(8):782.

14. Al-Sheyab NA, Alomari MA, Shah S, Gallagher R. "Class smoke-free" pledge impacts on nicotine dependence in male adolescents: A cluster randomized controlled trial. Journal of Substance Use. 2016;21(6):566-74. 
15. Mohammed M, Eggers SM, Alotaiby FF, de Vries N, de Vries H. Effects of a randomized controlled trial to assess the six-months effects of a school based smoking prevention program in Saudi Arabia. Preventive medicine. 2016;90:100-6.

16. Mohammadizeidi E, Pakpour A. Effectiveness of an educational intervention based on theory of planned behavior to reduce intentions to smoke among secondary school students. Journal of Research and Health. 2013;3(4):504-13.

17. Khazaee-Pool M, Pashaei T, Mansourian M, Qorbani M, Safari O, Shojaeizadeh D. School-based smoking prevention programs for middle school students in Nowshahr-Iran: A randomized controlled trial. International Journal of Pediatrics. 2016;4(11):3859-74.

18. Gharlipour Z, Hazavehei SMM, Moeini B, Nazari M, Beigi AM, Tavassoli E, et al. The effect of preventive educational program in cigarette smoking: Extended Parallel Process Model. Journal of education and health promotion. 2015;4.

19. Kelishadi R, Sarrafzadegan N, Sadri GH, Pashmi R, Mohammadifard N, Tavasoli AA, et al. Short-term results of a community-based program on promoting healthy lifestyle for prevention and control of chronic diseases in a developing country setting: Isfahan Healthy Heart Program. Asia Pacific Journal of Public Health. 2011;23(4):518-33.

20. Azizi F, Ghanbarian A, Momenan AA, Hadaegh F, Mirmiran P, Hedayati M, et al. Prevention of noncommunicable disease in a population in nutrition transition: Tehran Lipid and Glucose Study phase II. Trials. $2009 ; 10(1): 5$.

21. Mirmiran P, Mohammadi-Nasrabadi F, Omidvar N, Hosseini-Esfahani F, Hamayeli-Mehrabani H, Mehrabi Y, et al. Nutritional Knowledge, Attitude and Practice of Tehranian Adults and Their Relation to Serum Lipid and Lipoproteins: Tehran Lipid and Glucose Study. Annals of Nutrition and Metabolism. 2010;56(3):233-40.

22. McAlister A, Puska P, Salonen JT, Tuomilehto J, Koskela K. Theory and action for health promotion illustrations from the North Karelia Project. American Journal of Public Health. 1982;72(1):43-50.

23. Krauss RM, Eckel RH, Howard B, Appel LJ, Daniels SR, Deckelbaum RJ, et al. AHA Dietary Guidelines: revision 2000: A statement for healthcare professionals from the Nutrition Committee of the American Heart Association. Circulation. 2000;102(18):2284-99.

24. Bandura A, McClelland DC. Social learning theory: Englewood cliffs Prentice Hall; 1977.

25. Delshad M, Ghanbarian A, Ghaleh NR, Amirshekari G, Askari S, Azizi F. Reliability and validity of the modifiable activity questionnaire for an Iranian urban adolescent population. International journal of preventive medicine. 2015;6.

26. Thomas RE, McLellan J, Perera R. School-based programmes for preventing smoking. EvidenceBased Child Health: A Cochrane Review Journal. 2013;8(5):1616-2040.

27. Inchley J, Currie D. Growing up unequal: gender and socioeconomic differences in young people's health and well-being. Health Behaviour in School-aged Children (HBSC) study: international report from the 2013/2014 survey: World Health Organization; 2016. 
28. Baheiraei A, Cheraghi MA, Ebadi A, Soltani F. In their own voices: Iranian adolescent girls' views about smoking. National Journal of Physiology, Pharmacy and Pharmacology. 2018;8(3):1-6.

29. Kjeld SG, Glenstrup S, Bast LS. Gender and socioeconomic disparities in reasons for not smoking cigarettes among Danish adolescents. BMC Research Notes. 2021;14(1):33.

30. de Kleijn MJJ, Farmer MM, Booth M, Motala A, Smith A, Sherman S, et al. Systematic review of school-based interventions to prevent smoking for girls. Systematic Reviews. 2015;4(1):109.

31. Carson KV, Brinn MP, Labiszewski NA, Esterman AJ, Chang AB, Smith BJ. Community interventions for preventing smoking in young people. The Cochrane database of systematic reviews. 2011(7):Cd001291.

32. Christensen P. The health-promoting family: a conceptual framework for future research. Social science \& medicine (1982). 2004;59(2):377 - 87.

33. Huong LTT, Long TK, Anh LV, Cook M, Capra M. Decreasing In-home Smoking of Adults-Results from a School-based Intervention Program in Viet Nam. AIMS public health. 2016;3(4):863-79.

34. Siddiqi K, Huque R, Kanaan M, Ahmed F, Ferdous T, Shah S, et al. Children Learning About Secondhand Smoke (CLASS II): A Pilot Cluster Randomized Controlled Trial. Nicotine \& tobacco research: official journal of the Society for Research on Nicotine and Tobacco. 2019;21(5):670-7.

35. Intarut N, Chongsuvivatwong V, McNeil E. Effects of a school-based intervention program on attitude and knowledge of household members towards a smoke-free home: a cluster controlled trial. Asian Pac J Cancer Prev. 2016;17:1235-42.

36. Blanch C, Fernández E, Martínez-Sánchez JM, Ariza C, López MJ, Moncada A, et al. Impact of a multilevel intervention to prevent secondhand smoke exposure in schoolchildren: a randomized cluster community trial. Preventive medicine. 2013;57(5):585-90.

37. Brown N, Luckett T, Davidson PM, DiGiacomo M. Family-focussed interventions to reduce harm from smoking in primary school-aged children: A systematic review of evaluative studies. Prev Med. 2017;101:117-25.

38. Stamm-Balderjahn S, Groneberg DA, Kusma B, Jagota A, Schönfeld N. Smoking prevention in school students: positive effects of a hospital-based intervention. Dtsch Arztebl Int. 2012;109(44):746-52.

39. Nakkash R, Lotfi T, Bteddini D, Haddad P, Najm H, Jbara L, et al. A Randomized Controlled Trial of a Theory-Informed School-Based Intervention to Prevent Waterpipe Tobacco Smoking: Changes in Knowledge, Attitude, and Behaviors in 6th and 7th Graders in Lebanon. International journal of environmental research and public health. 2018;15(9).

40. Lopez A, Eissenberg T, Jaafar M, Afifi R. Now is the time to advocate for interventions designed specifically to prevent and control waterpipe tobacco smoking. Addictive behaviors. 2017;66:41-7.

\section{Figures}




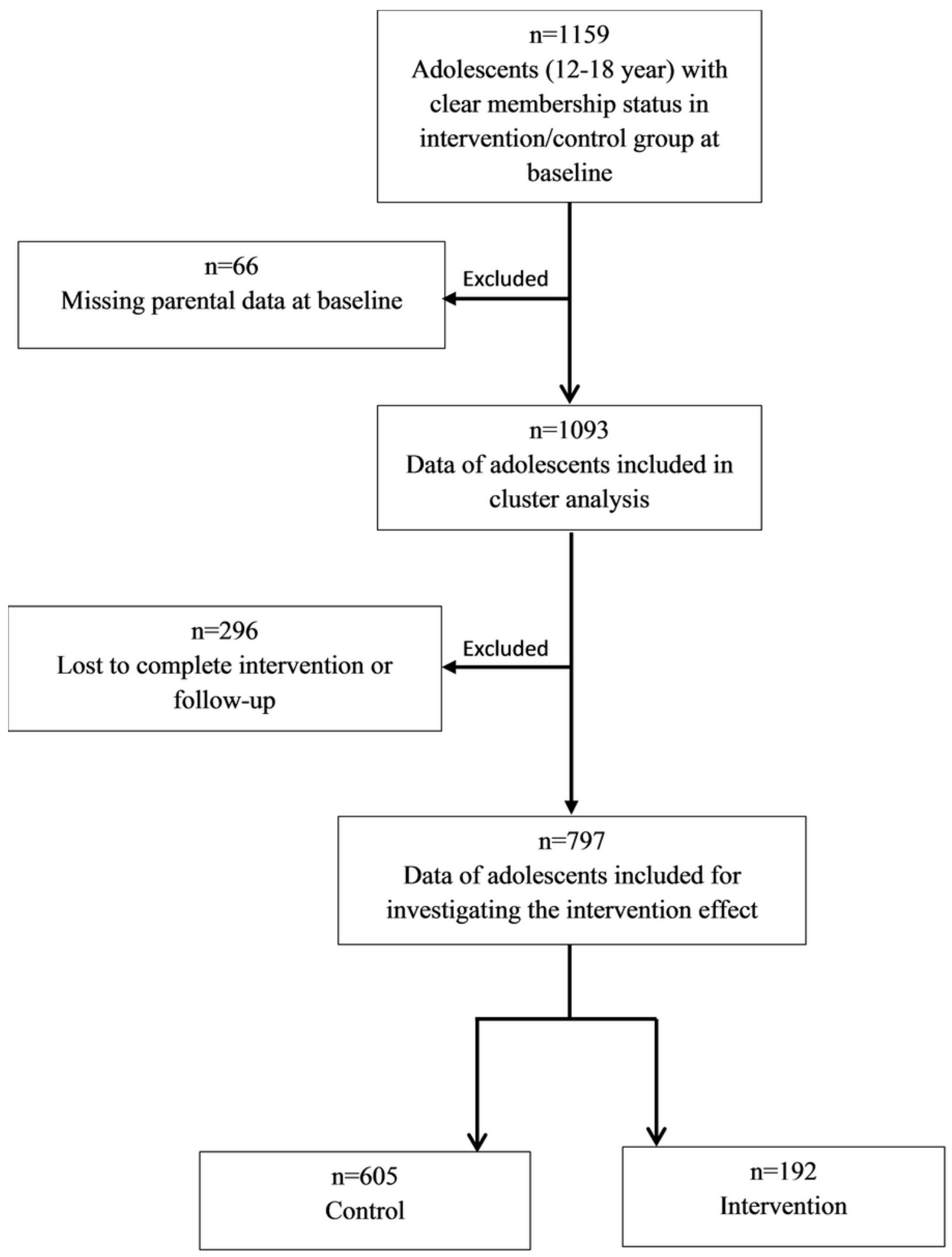

Figure 1

Sampling frame of the study 
a)

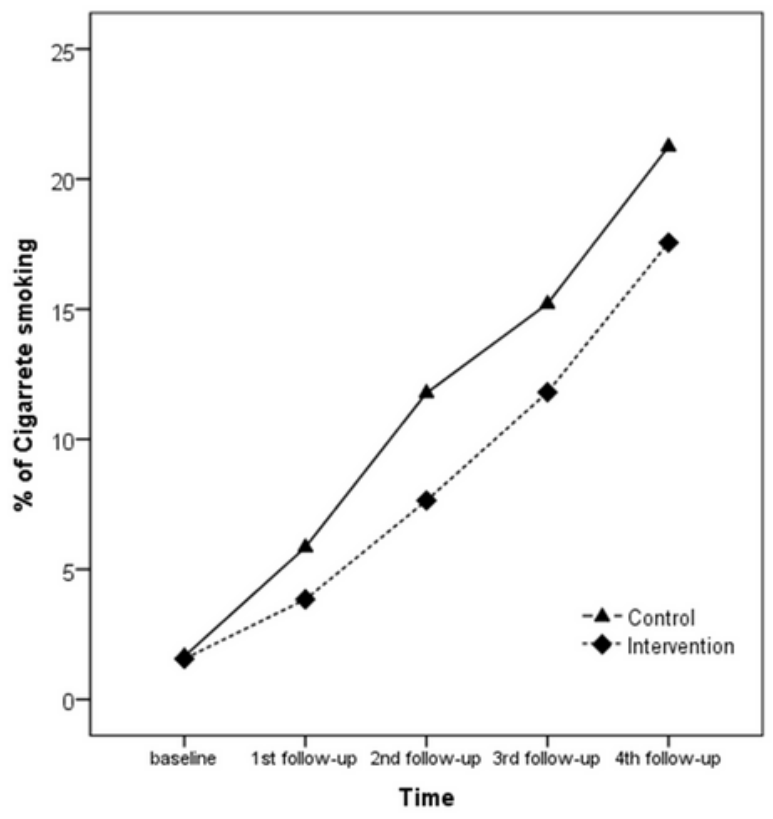

b)

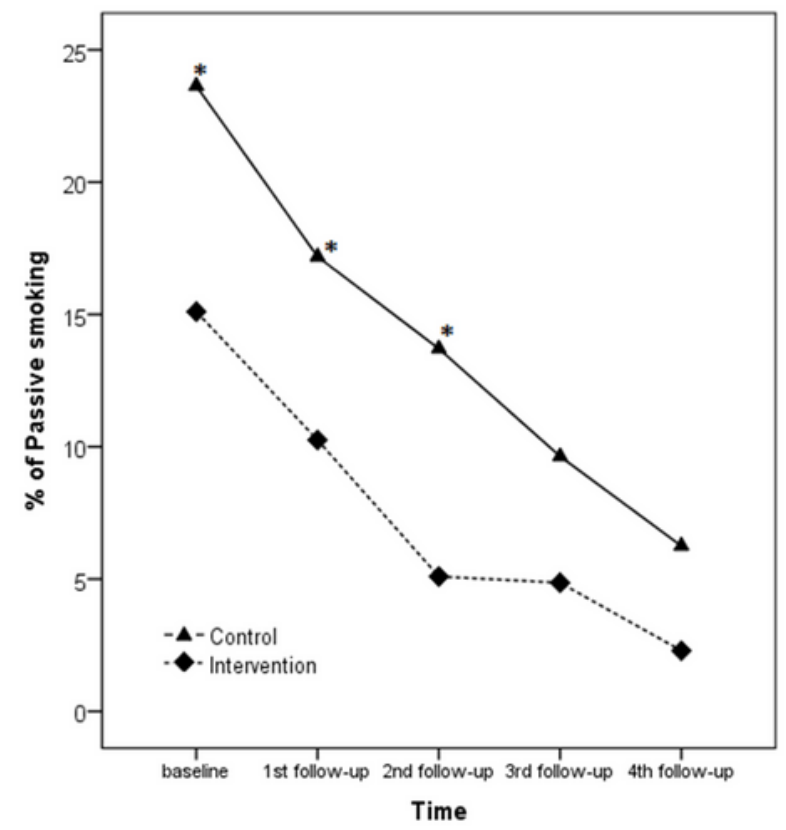

c)

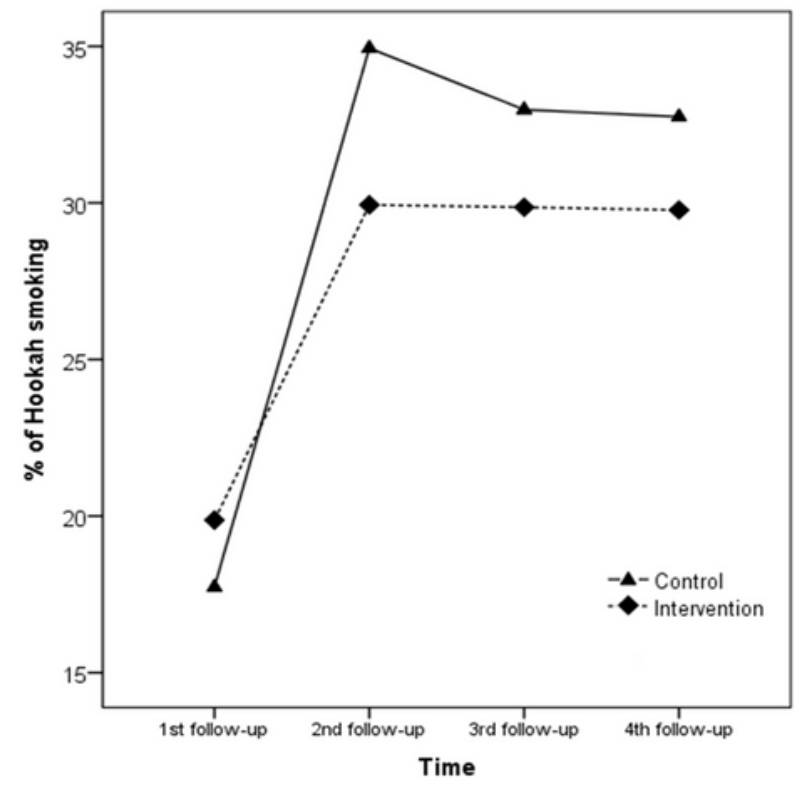

Figure 2

Prevalence of smoking status over follow up: Comparing control and intervention groups. * Values significantly differ between the control and intervention groups $(P<0.05)$

\section{Supplementary Files}


This is a list of supplementary files associated with this preprint. Click to download.

- Supplementalmaterial.docx 